University of Nebraska - Lincoln

DigitalCommons@University of Nebraska - Lincoln

\title{
A Comparison of Melengestrol Acetate Fed at Two Dose Levels to Feedlot Heifers
}

\author{
G. E. Sides \\ Pfizer Animal Health, Kalamazoo, MI \\ J. T. Vasconcelos \\ University of Nebraska, Scottsbluff \\ R. C. Borg \\ Pfizer Animal Health, Kalamazoo, MI
}

O. A. Turgeon

Bos Technica Research Services Inc., Salina, KS

W. C. Koers

Bos Technica Research Services Inc., Salina, KS

See next page for additional authors

Follow this and additional works at: https://digitalcommons.unl.edu/panhandleresext

Part of the Agriculture Commons

Sides, G. E.; Vasconcelos, J. T.; Borg, R. C.; Turgeon, O. A.; Koers, W. C.; Davis, M. S.; Vander Pol, K.; Weigel, D. J.; and Tucker, C. M., "A Comparison of Melengestrol Acetate Fed at Two Dose Levels to Feedlot Heifers" (2009). Panhandle Research and Extension Center. 54.

https://digitalcommons.unl.edu/panhandleresext/54

This Article is brought to you for free and open access by the Agricultural Research Division of IANR at DigitalCommons@University of Nebraska - Lincoln. It has been accepted for inclusion in Panhandle Research and Extension Center by an authorized administrator of DigitalCommons@University of Nebraska - Lincoln. 


\section{Authors}

G. E. Sides, J. T. Vasconcelos, R. C. Borg, O. A. Turgeon, W. C. Koers, M. S. Davis, K. Vander Pol, D. J. Weigel, and C. M. Tucker 


\title{
A \\ Comparison of Melengestrol Acetate Fed at Two Dose Levels to Feedlot Heifers
}

\author{
G. E. Sides, ${ }^{\star}$ PAS, J. T. Vasconcelos, $\dagger^{1}$ PAS, R. C. Borg, ${ }^{\star 2}$ O. A. Turgeon,‡ PAS, \\ W. C. Koers, $\ddagger$ PAS, M. S. Davis, $\ddagger$ K. Vander Pol, $\ddagger$ PAS, D. J. Weigel, ${ }^{*}$ and C. M. Tucker* \\ *Pfizer Animal Health, Kalamazoo, MI 49001; †Panhandle Research and Extension Center, \\ University of Nebraska, Scottsbluff 69361; and ‡Bos Technica Research Services Inc., \\ Salina, KS 67401
}

\begin{abstract}
$A$ randomized complete block design was used to compare the effects of feeding melengestrol acetate (MGA) at 0.4 (0.4M) and $0.5(0.5 \mathrm{M}) \mathrm{mg} / \mathrm{d}$ per head on feedlot performance, estrus activity, and carcass characteristics of commercial beef heifers ( $n=1,418 ; 10$ pens) treatment). Within $48 \mathrm{~h}$ of arrival at the research site, heifers were assigned to treatment, processed according to feedlot protocol, and administered an abortifacient. After adaptation to a $95 \%$ concentrate diet, MGA was supplied at either 0.4 or $0.5 \mathrm{mg} / \mathrm{head}$ daily. Estrus activity was monitored twice daily and summarized as a count of heifers showing estrus within a pen over each 21-d interval throughout the study. Dry matter intake, $A D G, G: F$, and all other carcass measurements were not different $(P>0.10)$ between treatments. Overall treatment effects were different only for estrus activity $(P=0.03 ; 3.2$ vs. 2.1\% for $0.4 M$ and $0.5 M$, respectively) and tended to be different for the percentage of dark-cutting carcasses $(P=0.10 ; 3.0$ vs. $1.7 \%$ for $0.4 \mathrm{M}$ and $0.5 \mathrm{M}$, respec-

\footnotetext{
${ }^{1}$ Corresponding author: jvasconcelos2@unl. edu

${ }^{2}$ Current address: Cobb-Vantress Inc., Siloam Springs, AR 72761.
}

tively). Results of this study showed little difference between treatment groups for performance and carcass characteristics of feedlot heifers. The decrease in estrus activity and percentage of dark-cutting carcasses, however, may suggest an economic advantage of feeding a higher level of MGA to finishing heifers.

Key words: beef cattle, carcass, feedlot, heifer, melengestrol acetate, performance

\section{INTRODUCTION}

Melengestrol acetate (MGA; Pfizer Animal Health, New York, NY) is an orally active progestogen that has been commercially available since 1968 as a feed additive to improve feed utilization and growth rate, and to suppress expression of estrus in feedlot heifers (Bloss et al., 1966; O'Brien et al., 1968; Lauderdale, 1983). However, current production scenarios including different nutrition strategies, implant strategies, feed additives, marketing specifications, and cattle genotypes result in a different level of production expectation than for cattle produced a few decades ago.

To achieve optimal feed conversion and growth and the highest degree of estrus suppression from MGA, a dose level of 0.35 to $0.50 \mathrm{mg} / \mathrm{d}$ per heifer has been recommended (Bloss et al., 1966; Zimbelman and Smith, 1966).

Differences in performance associated with varying dosages of MGA within its recommended levels have not received much attention under current management practices. Therefore, the objective of this study was to compare the effects of MGA supplied at 0.4 versus $0.5 \mathrm{mg} / \mathrm{d}$ per heifer in the finishing ration on estrus activity, ADG, G:F, and carcass characteristics of finishing feedlot heifers.

\section{MATERIALS AND METHODS}

\section{Animal Management}

This study was conducted in a manner consistent with applicable laws and regulations governing the humane care of animals. Heifers were observed at least once daily to ensure animals were healthy, and, if any abnormality was detected, to ensure prompt and adequate treatment by a qualified veterinarian.

Commercial feedlot heifers of mixed breeds ( $\mathrm{n}=1,418 ; 9$ to 14 mo of age; initial $\mathrm{BW}=290 \pm 1.9 \mathrm{~kg}$ ) were used in a randomized complete block design study conducted at a commercial research facility near Syra- 
cuse, Kansas (Bos Technica Research Services Inc.). Experimental blocks were composed of 2 pens based on location, with a total of 20 pens (10 blocks). Heifers were housed in dirt pens that were $21.3 \times 91.4 \mathrm{~m}$ in size, with individual pen flow water tanks $(1 \times 3.7 \mathrm{~m})$ and 19.5 linear meters of fence-line bunk space per pen. Cattle were processed by arrival date (March 5 through March 28, 2007) and randomly assigned 10 head at a time to pens within an experimental block until the desired head count in each pen was attained (70 to 75 heifers/ pen). Each block consisted of 2 pens randomly assigned to 1 of $2 \mathrm{MGA}$ dose levels: $0.4(\mathbf{0 . 4 M})$ or $0.5(\mathbf{0 . 5 M})$ $\mathrm{mg} / \mathrm{d}$ per head.

Based on evaluation of heifers upon arrival, cattle were excluded from the study if they required therapy for any injury or nonrespiratory disease, exhibited clinical signs of bovine respiratory disease, exhibited conditions that could have affected their response to bovine respiratory disease treatments, were noticeably pregnant, or were bulls or steers. At the beginning of the study, there were 709 cattle in each treatment. Five steers were identified $(\mathrm{n}=3$ in the $0.4 \mathrm{M}$ group, and $\mathrm{n}=2$ in the $0.5 \mathrm{M}$ group) and removed from the study after initial enrollment. One heifer was killed because of injury, and 6 heifers died as a result of digestive problems (bloat). A total of 5 additional heifers were rejected from the study shortly after enrollment for chronic respiratory problems, founder, abscesses, or mechanical problems. Heifers completing the study were slaughtered at a commercial beef-packing facility (National Beef, Liberal, KS).

Within $48 \mathrm{~h}$ after allotment to the research pens, heifers were processed and received a unique identification number and tag with both a visual drop-down tag and an electronic tag in the left ear. For each heifer, pen number, date of enrollment, identification number, and BW were recorded. Heifers were vaccinated upon arrival for viral (Bovi-Shield Gold 5, Pfizer Animal Health) and clostridial (Ultra Bac 7, Pfizer Animal Health) diseases and were treated for parasites (Durasect II and Dectomax Injectable, Pfizer Animal Health). An abortifacient (Lutalyse, Pfizer Animal Health) was administered to all heifers. Each heifer was implanted with $8 \mathrm{mg}$ estradiol and $80 \mathrm{mg}$ of trenbolone acetate (Revalor-IH, Intervet Inc., Millsboro, DE) in the right ear. Heifers were reimplanted with $200 \mathrm{mg}$ trenbolone acetate (Finaplix-H, Intervet Inc.) in the left ear at either 105 (blocks 1 through 5) or 112 (blocks 6 through 10) d before slaughter.

\section{Diet and Feeding}

Diets were formulated to meet or exceed NRC (1996) requirements and fed for ad libitum consumption. Heifers were adjusted to a $95 \%$ concentrate final diet using a series of 3 step-up diets, with MGA included only in the final diet (Table 1). Heifers were adjusted to the finishing diet within 5 wk after arrival. Feed additives included tylosin at $90 \mathrm{mg} / \mathrm{d}$ per head (Tylan, Elanco Animal Health, Greenfield, IN) and monensin (36 g/ton; Rumensin, Elanco Animal Health). Treatment doses of MGA (MGA 200, Pfizer Animal Health) were included at 0.4 or $0.5 \mathrm{mg} / \mathrm{d}$ per head. Ractopamine hydrochloride $(200 \mathrm{mg} / \mathrm{d}$ per head; Optaflexx, Elanco Animal Health) was included in the diets of all heifers $28 \mathrm{~d}$ before slaughter. All microingredients were hand-weighed on analytical platform scales (Model ALC 2100.2, Acculab, Bradford, MA) to the nearest $0.01 \mathrm{~g}$ before their addition to the ration. Additives were placed in a flush bowl and mixed with approximately $20 \mathrm{~L}$ of water for $45 \mathrm{~s}$. Diets were sampled daily and analyzed for DM content, and weekly composites of the daily samples were analyzed for nutrient content (SDK Laboratory, Hutchinson, KS) and monensin concentrations (Eurofins Laboratory, Memphis, TN). Cattle were fed 3 times daily and the amount of feed delivered to each pen was recorded for each feeding. Feed weigh-backs were recorded for each pen as needed throughout the study. Weighed-back feed was determined on

\section{Table 1. Nutrient composition of experimental diet (DM basis)}

\begin{tabular}{lrr} 
& \multicolumn{2}{c}{ Treatment $^{1}$} \\
\cline { 2 - 3 } Item & $\mathbf{0 . 4 M}$ & $\mathbf{0 . 5 M}$ \\
\hline Ingredient, \% & & \\
Flaked corn & 84.5 & 84.5 \\
Alfalfa hay & 5.1 & 5.1 \\
Choice white grease $^{2}$ & 4.2 & 4.2 \\
Supplement & \\
Analyzed nutrient & 6.2 & 6.2 \\
composition, \% & & \\
DM & & \\
CP & 80.69 & 80.55 \\
NPN & 12.69 & 12.78 \\
Crude fiber & 2.50 & 2.56 \\
Fat & 4.18 & 4.24 \\
Ca & 7.51 & 7.64 \\
P & 0.71 & 0.72 \\
& 0.27 & 0.28
\end{tabular}

Treatments: $0.4 \mathrm{M}=0.4 \mathrm{mg}$ of melengestrol acetate per head daily; $0.5 \mathrm{M}=0.5 \mathrm{mg}$ of melengestrol acetate per head daily.

${ }^{2}$ Supplement contained at least $74 \%$ CP and not more than $44 \%$ NPN. All diets contained tylosin at $90 \mathrm{mg} / \mathrm{d}$ per head (Tylan, Elanco Animal Health, Greenfield, IN) and $36 \mathrm{~g} / \mathrm{ton}$ of monensin (Rumensin, Elanco Animal Health).

a DM basis using a laboratory convection oven on site. Total feed intake per pen was calculated on a DM basis as the amount of feed offered minus the weighed-back portion of feed. Daily feed intake was then calculated as total feed intake divided by total animal days, where total animal days was equal to the number of days each heifer was in its home pen from start to finish of the study, totaled for each pen.

\section{Daily Observations}

Daily observations of abnormal conditions (morbidity, mortality, and adverse reactions) were performed by trained personnel. Animals that required treatment were taken from their pens, treated, and returned to their home pens according to standard feedlot therapy. Animals that either died or were killed underwent necropsy by a qualified veterinarian to 


\section{Table 2. Performance and estrus activity of heifers fed different levels of melengestrol acetate}

\begin{tabular}{|c|c|c|c|c|}
\hline \multirow[b]{2}{*}{ Item } & \multicolumn{2}{|c|}{ Treatment $^{1}$} & \multirow[b]{2}{*}{$\mathrm{SE}^{2}$} & \multirow[b]{2}{*}{$P$-value } \\
\hline & $0.4 \mathrm{M}$ & $0.5 \mathrm{M}$ & & \\
\hline Pens & 10 & 10 & - & - \\
\hline No. of animals & 709 & 709 & - & - \\
\hline No. of animals removed & 5 & 5 & - & - \\
\hline No. dead & 2 & 5 & - & - \\
\hline \multicolumn{5}{|l|}{ Live performance } \\
\hline Initial BW, kg & 290 & 290 & 1.88 & 0.97 \\
\hline $\mathrm{DMI}, \mathrm{kg}$ & 7.30 & 7.32 & 0.06 & 0.68 \\
\hline Final BW, ${ }^{3} \mathrm{~kg}$ & 524 & 524 & 1.88 & 0.92 \\
\hline Total BW gain, kg & 234 & 233 & 2.53 & 0.97 \\
\hline $\mathrm{ADG}, \mathrm{kg}$ & 1.33 & 1.33 & 0.01 & 0.97 \\
\hline $\mathrm{G}: \mathrm{F}$ & 0.18 & 0.18 & 0.01 & 0.64 \\
\hline Observed estrus activity, ${ }^{4} \%$ & $3.2(0.42)$ & $2.1(0.32)$ & - & 0.03 \\
\hline
\end{tabular}

${ }^{1}$ Treatments: $0.4 \mathrm{M}=0.4 \mathrm{mg}$ of melengestrol acetate per head daily; $0.5 \mathrm{M}=0.5 \mathrm{mg}$ of melengestrol acetate per head daily.

${ }^{2} \mathrm{SE}=$ standard errors from mixed model analysis.

${ }^{3}$ Final BW was shrunk (applied a $4 \%$ pencil shrink on actual BW).

${ }^{4}$ Observed estrus activity least squares estimates were calculated from a generalized mixed model analysis and represent the percentage of heifers showing visual signs of estrus across all 21-d periods. Estimates of SE for each treatment are listed in parentheses.

assess the cause of death. For heifers removed from the study, a qualified veterinarian diagnosed the cause of removal.

Estrus detection observations were conducted twice daily (morning and afternoon) for approximately $10 \mathrm{~min}$ by trained personnel. Frequency of estrus activity was recorded while heifers were fed the finishing diet. Estrus was determined by heifers exhibiting standing heat. Observed estrus activity was recorded on a daily basis as the total number of heifers exhibiting standing estrus within a pen during each observation.

\section{Live Performance}

Pen BW was recorded at processing and just before slaughter. Initial $\mathrm{BW}$ was calculated as the pen BW at processing divided by the number of heifers placed. Final shrunk BW was calculated as the pen BW before slaughter $\times 0.96$ divided by the number of heifers shipped for slaughter. An adjustment of $4 \%$ was applied to final pen BW to account for shrink associated with rumen fill. Total pen BW gain was calculated as the differences between final and initial BW and daily BW gain was calculated as total BW gain divided by the average number of days on feed.

\section{Carcass Characteristics}

Heifers were slaughtered by block on 1 of $2 \mathrm{~d}$ (September 4 or 17, 2007). All heifers within a block were slaughtered on the same day. Average days on feed was 176 and ranged from 166 to 182. Carcass data were collected at the time of slaughter by USDA meat graders and an independent carcass collection team (Cattle Trail Inc., Johnson, KS). Carcass measures included hot carcass weight, dressing percentage, 12th-rib fat thickness, LM area, marbling score, USDA QG and YG, liver abscess incidence, KPH, empty body fat percentage, cutability percentage, and presence of darkcutting carcasses within a pen. Liver abscesses were scored according to the 3-point scale described by Elanco (1974).

\section{Statistical Analysis}

The response variables of interest were initial and final BW, ADG, total BW gain, DMI, G:F, estrus activity, and carcass variables. Pen was the experimental unit for all variables. Mixed model procedures (SAS Institute Inc., Cary, NC) were used that included the random effects of block, the fixed effects of treatment, and treatment $\times$ block as the error term. Tests of treatment differences were based on least significant differences. Carcass measures that were categorically expressed included USDA QG and YG, liver abscesses, and dark-cutting carcasses. The response variables for categorically expressed carcass measures were evaluated as proportional carcass measures within pen and were analyzed using the GLIMMIX procedure (SAS Institute Inc.) with the same mixed model described above. Treatment differences for carcass quality and YG were based on the percentage of carcasses within a pen that graded Choice or better and had a YG of less than 4 , respectively. Estrus activity was evaluated daily throughout the study and was divided into 21-d intervals for statistical evaluation. The total number of heifers within a pen that were observed showing standing heat in each 21-d interval was calculated and the totals were analyzed with a repeated-measures generalized mixed model that included the fixed effects of treatment, period of study (21-d interval), and the treatment $\times$ period of study interaction and the random effects of block, the block $\times$ treatment interaction, and residual error. All generalized mixed model procedures assumed a logit link function and a binomial distribution, and estimates of least significant differences and SE were back-transformed to their observed scale.

\section{RESULTS AND DISCUSSION}

Results of heifer growth performance and feed consumption are presented in Table 2 for each treatment group. Body weights were simi- 
lar between the 2 treatment groups, with initial and final BW means of 290 and $524 \mathrm{~kg}$, respectively, for the $0.4 \mathrm{M}$ and $0.5 \mathrm{M}$ groups. Differences between $0.4 \mathrm{M}$ and $0.5 \mathrm{M}$ heifers were not present $(P>0.10)$ for DMI, total BW gain, ADG, or G:F. Removing dead and rejected calves from the analysis of performance did not influence performance results; therefore, results without the dead or rejected calves are not reported. Observation of estrus activity throughout the study revealed a higher frequency of heifers showing estrus (standing heat) in $0.4 \mathrm{M}(3.2 \%)$ compared with $0.5 \mathrm{M}$ $(2.1 \% ; P=0.03)$ across all 21 -d periods such that the treatment $\times$ period interaction was not significant $(P=$ $0.83)$.

The effect of different dosages of MGA on heifer performance and estrus suppression were evaluated during the early years of MGA development (Zimbelman and Smith, 1966; Young et al., 1969). Although the labeled dosage range for MGA is
0.25 to $0.50 \mathrm{mg} / \mathrm{d}$ per head (US Food and Drug Administration, 1968), studies from Bloss et al. (1966) and Zimbelman and Smith (1966) suggest a more refined level of 0.35 to $0.50 \mathrm{mg} / \mathrm{d}$ per head for the optimal response in growth, feed efficiency, and estrus suppression. Results of this study showed little difference between treatment groups for growth, feed utilization, and carcass characteristics, which agrees with previous data that showed little distinction in performance at MGA levels between 0.35 and $0.50 \mathrm{mg} / \mathrm{d}$ per head (Bloss et al., 1966; Zimbelman and Smith, 1966). The use of MGA in finishing diets may improve heifer performance by enhancing feed utilization through optimizing hormonal mechanisms that inhibit the preovulatory surge of luteinizing hormone, which prevents ovulation of dominate follicles (Imwalle et al., 2002). Purchas et al. (1971) concluded that higher levels of estrogen in heifers treated with MGA plays a role in growth stimulation.

\section{Table 3. Carcass performance of heifers fed different levels of melengestrol acetate}

\begin{tabular}{|c|c|c|c|c|}
\hline \multirow[b]{2}{*}{ Item } & \multicolumn{2}{|c|}{ Treatment $^{1}$} & \multirow[b]{2}{*}{ SE } & \multirow[b]{2}{*}{$P$-value } \\
\hline & $0.4 \mathrm{M}$ & $0.5 \mathrm{M}$ & & \\
\hline \multicolumn{5}{|l|}{ Carcass measure } \\
\hline Dressing percentage & 65.1 & 65.0 & 0.09 & 0.21 \\
\hline Hot carcass weight, $\mathrm{kg}$ & 341 & 340 & 1.44 & 0.59 \\
\hline Marbling score ${ }^{2}$ & 299 & 298 & 3.13 & 0.92 \\
\hline 12th-rib fat thickness, $\mathrm{cm}$ & 1.29 & 1.32 & 0.03 & 0.29 \\
\hline $\mathrm{KPH}, \%$ & 2.24 & 2.20 & 0.03 & 0.10 \\
\hline LM area, $\mathrm{cm}^{2}$ & 91.2 & 90.2 & 0.48 & 0.10 \\
\hline Calculated YG & 2.56 & 2.64 & 0.05 & 0.13 \\
\hline Empty body fat, $\%$ & 26.7 & 26.9 & 0.18 & 0.19 \\
\hline Cutability, \% & 50.8 & 50.6 & 0.11 & 0.13 \\
\hline \multicolumn{5}{|l|}{ Proportional carcass measure ${ }^{3}$} \\
\hline Dark-cutting carcasses, $\%$ & $3.0(1.10)$ & $1.7(0.68)$ & - & 0.10 \\
\hline QG Prime and Choice, \% & $37.9(2.08)$ & $37.3(2.07)$ & - & 0.84 \\
\hline YG 1,2, or $3, \%$ & $82.9(2.46)$ & $85.4(2.22)$ & - & 0.24 \\
\hline Abscessed livers, $\%$ & $6.4(1.14)$ & $8.4(1.37)$ & - & 0.18 \\
\hline
\end{tabular}

${ }^{1}$ Treatments: $0.4 \mathrm{M}=0.4 \mathrm{mg}$ of melengestrol acetate/head daily; $0.5 \mathrm{M}=0.5 \mathrm{mg}$ of melengestrol acetate/head daily.

$2300=$ Slight $^{0} ; 400=$ Small $^{0} ; 500=$ Modest $^{0}$.

${ }^{3}$ Treatment least squares means for proportional carcass measures were calculated from a generalized linear mixed model analysis. Estimates of SE for each treatment are listed in parentheses.
However, in an earlier study, Purchas et al. (1970) suggested MGA stimulates growth through suppressed adrenal cortical activity. Likewise, Moseley et al. (2003) showed a response to growth in MGA-treated steers $(0.1$ $\mathrm{mg} / \mathrm{d}$ ) with increased fat deposition and decreased LM area, indicating that part of the effects of MGA may involve a nonfollicular mechanism. Results of the current study indicate that any mechanisms by which MGA acts on growth, feed conversion, or carcass characteristics are not sensitive to dose variations between 0.4 and $0.5 \mathrm{mg} / \mathrm{d}$.

A major benefit of feeding MGA to feedlot heifers is through the suppression of estrus. Heifers expressing physical signs of estrus show increased physical activity (increased pedal activity and mounting) and physiological stress associated with recurring ovulation. Early titration studies of MGA indicated the minimum effective dose to inhibit ovulation in most cattle was $0.42 \mathrm{mg}$, with complete suppression of ovulation occurring with a daily dose of $0.50 \mathrm{mg}$ (Zimbelman and Smith, 1966). Young et al. (1969) also showed a minimum dose for optimal suppression of estrus of $0.4 \mathrm{mg} / \mathrm{d}$ in Angus heifers. Young et al. (1969) fed MGA at a dose of 0.0, $0.2,0.4$, and $0.6 \mathrm{mg} / \mathrm{d}$ per calf for 154 $\mathrm{d}$ and reported at least one incidence of observed estrus in 95.0, 70.6, 15.0, and $0.0 \%$ of the heifers, respectively, for each dose. In the current study, estrus activity was suppressed in both $0.4 \mathrm{M}$ and $0.5 \mathrm{M}$ groups when compared with negative controls of previous studies (Zimbelman and Smith, 1966; Young et al., 1969), with fewer incidences of estrus associated with the $0.5 \mathrm{M}$ group. In the present study, a lower frequency of observed estrus at the 0.4-mg dose was observed compared with the results of Young et al. (1969).

Heifers fed MGA for an extended period of time are expected to return to estrus approximately 3 to $7 \mathrm{~d}$ after MGA withdrawal (Zimbelman and Smith, 1966; Roussel and Beatty, 1969; Wettemann et al., 1973). However, the effects of temporary 
intervals of reduced MGA intake on ovulation are unclear. Young et al. (1969) speculated that heifers broke through the estrus suppression effects of MGA and ovulated because of inconsistent consumption of MGA throughout the feeding interval of their field trial. It was suggested that maximum estrus suppression required heifers not to miss a single MGA feeding. In the presence of an antagonistic relationship between daily feed intake variability and estrus suppression in MGA-fed heifers, we might expect to see more estrus activity in groups fed at a lower MGA doses. In the current study, daily feed intake was not recorded for individual animals, and results reported herein do not validate this relationship between feed intake variation and estrus suppression.

Overall carcass performance did not vary with MGA dose level $(P>0.10)$, with the exception of dark-cutting carcasses. Distributions of carcass USDA QG and YG as well as liver abscesses are presented in Tables 3 and 4. Carcass quality was consistent between the 2 treatment groups, with the percentage of carcasses grading Choice or better within a pen ranging from 31.4 to $48.6 \%$ and 31.1 to $55.7 \%$ for $0.4 \mathrm{M}$ and $0.5 \mathrm{M}$, respectively (data not shown). Distributions of YG were also similar, with the percentage of carcasses having a $\mathrm{YG}<4$ ranging from 64.3 to $91.4 \%$ and 67.6 to $91.8 \%$ for $0.4 \mathrm{M}$ and $0.5 \mathrm{M}$, respectively (data not shown). There was a trend ( $P$ $=0.10)$ for $0.4 \mathrm{M}$ heifers to exhibit a greater number of dark-cutting carcasses $(3.0 \%)$ compared with $0.05 \mathrm{M}$ heifers (1.7\%). Estimated mean values for calculated YG resulted in 0.09 YG units higher for $0.5 \mathrm{M}$; however, this difference was not significant $(P=$ $0.13)$.

Bloss et al. (1966) and Lauderdale (1983) reported no difference in carcass characteristics in heifers fed different MGA dose levels, which is in agreement with data from the present study. Others, however, have reported increases in external fat deposition, reduced LM area (Mader and Lechtenberg, 2000), or greater marbling scores (Macken et al., 2003;
Kreikemeier and Mader, 2004) in MGA-fed heifers compared with heifers not fed MGA. The National Beef Quality Audit-2000 (McKenna et al., 2002) reported $2.3 \%$ dark-cutting beef carcasses in the US market. Differences in the frequency of darkcutting carcasses in this study only approached significance (3.0 and 1.7\% for $0.4 \mathrm{M}$ and $0.5 \mathrm{M}$, respectively; $P=$ 0.09 ), but the differences do support an economic advantage for $0.5 \mathrm{M}$ heifers. Based on grid-pricing markets reported by the USDA (2008), the average discount placed on dark-cutting carcasses was $\$ 0.6486 / \mathrm{kg}$ of carcass weight (range of $\$ 0.3307$ to $\$ 1.21$ ). For this example (\$0.6486) and results reported herein, the differences in carcass value for a pen of 100 heifers fed at the $0.4 \mathrm{M}$ versus $0.5 \mathrm{M}$ dose, both with a hot carcass average weight of $340 \mathrm{~kg}$, would be $\$ 311.98$ more for the $0.5 \mathrm{M}$ group $[100$ heifers $\times(1.7 \% \times$ $340 \mathrm{~kg} \times \$ 0.6486)-(3.0 \% \times 340 \mathrm{~kg}$ $\times \$ 0.6486)=-\$ 311.98]$.

The relationships between dark-cutting carcasses and environmental factors (management, season, sex) have been documented (Kreikemeier et al., 1998; Scanga et al., 1998). However, the link between dark-cutting carcasses and heifer estrus is not clear. Scanga et al. (1998) evaluated commercial cattle over a 3 -yr period $(\mathrm{n}=11,663$ pens of steers, $\mathrm{n}=3,645$ pens of heifers) and reported sex as having a significant effect on dark-cutting beef, with heifers averaging $0.3 \%$ more dark cutters per pen than steers $(0.08 \%$ vs. $0.38 \% \pm 0.001)$ for steers and heifers, respectively, throughout the study). Voisinet et al. (1997) indicated heifers were more excitable than older parous females. Kenny and Tarrant (1988) reported a negative relationship between muscle glycogen and estrus activity in heifers. Decreased muscle glycogen inhibits the reduction of muscle $\mathrm{pH}$ and results in dark-cutting beef (Ashmore et al., 1973). Romans et al. (1988) showed heifers slaughtered during estrus tended to have darker cutting carcasses. The causal effects of these relationships have yet to be determined.

\section{Table 4. Descriptive summary of carcass USDA QG and YG categories and the proportion of abscessed livers of heifers fed different levels of melengestrol acetate}

\begin{tabular}{lrr} 
& \multicolumn{2}{c}{ Treatment $^{1}$} \\
\cline { 2 - 3 } Item & $\mathbf{0 . 4 M}$ & $\mathbf{0 . 5 M}$ \\
\hline Carcass & 702 & 699 \\
QG distribution, ${ }^{2} \%$ & & \\
Prime & 0.4 & 0.4 \\
Choice & 37.5 & 36.9 \\
Select & 55.5 & 58.5 \\
Other & 6.6 & 4.2 \\
YG distribution, ${ }^{2} \%$ & & \\
YG 1 & 7.5 & 7.0 \\
YG 2 & 33.8 & 29.9 \\
YG 3 & 41.0 & 47.9 \\
YG 4 & 15.2 & 12.6 \\
YG 5 & 2.4 & 2.6 \\
Liver abscesses & & \\
score, ${ }^{3} \%$ & & \\
0 & 93.5 & 91.5 \\
1 & 4.7 & 7.0 \\
2 & 0.5 & 0.4 \\
3 & 1.3 & 1.1 \\
\hline
\end{tabular}

${ }^{1}$ Treatments: $0.4 \mathrm{M}=0.4 \mathrm{mg}$ of melengestrol acetate per head daily; $0.5 \mathrm{M}=0.5 \mathrm{mg}$ of melengestrol acetate per head daily.

${ }^{2} U S D A$ grades were assigned by USDA graders as reported by the packing plant; distributions represent the percentage of carcasses assigned a given grade.

${ }^{3}$ Abscess scoring system (Elanco, 1974): 0 = healthy liver; $1=1$ to 4 small abscesses; 2 = 1 to 4 medium abscesses; and $3=1$ or more large abscesses.

\section{IMPLICATIONS}

There have been numerous changes in the feedlot industry since MGA was first introduced in 1968. These include grain processing, breed type, mature BW, implant regimen, adaptation strategies, and dietary energy concentration. Despite all these changes, MGA appears to perform efficiently on a feedlot performance basis at the same FDA-approved lev- 
els as when initially approved for use in 1968. Feeding MGA at the highest labeled dose may be economically beneficial in reducing the frequency of estrus activity and any associated dark-cutting carcasses within a group of heifers. However, variations in daily individual heifer feed intake need to be evaluated further to determine its influence on breaks in estrus suppression and dark-cutting carcasses in heifers fed at lower MGA doses.

\section{LITERATURE CITED}

Ashmore, C. R., F. Carroll, L. Doerr, G. Tompkins, H. Stokes, and W. Parker. 1973. Experimental prevention of dark-cutting meat. J. Anim. Sci. 36:33.

Bloss, R. E., J. I. Northam, L. W. Smith, and R. G. Zimbelman. 1966. Effects of oral melengestrol acetate on the performance of feedlot cattle. J. Anim. Sci. 25:1048.

Elanco. 1974. Tylan premix for beef cattle. Technical B Manual. Elanco, Indianapolis, IN.

Imwalle, D. B., D. L. Fernandez, and K. K. Schillo. 2002. Melengestrol acetate blocks the preovulatory surge of luteilizing hormone, the expression of behavioral estrus, and ovulation in beef heifers. J. Anim. Sci. 80:1280.

Kenny, F. J., and P. V. Tarrant. 1988. The effect of oestrus behaviour on muscle glycogen concentration and dark-cutting in beef heifers. Meat Sci. 22:21.

Kreikemeier, K. K., J. A. Unruh, and T. P. Eck. 1998. Factors affecting the occurrence of dark-cutting beef and selected carcass traits in finished beef cattle. J. Anim. Sci. 76:388.

Kreikemeier, W. M., and T. L. Mader. 2004. Effects of growth-promoting agents and season on yearling feedlot heifer performance. J. Anim. Sci. 82:2481.
Lauderdale, J. W. 1983. Use of MGA (melengestrol acetate) in animal production. p. 193 in Anabolics in Animal Production: Public Health Aspects, Analytical Methods and Regulation. Office International des Epizooties, Paris, France.

Macken, C. N., C. T. Milton, T. J. Klopfenstein, B. D. Dicke, and D. E. McClellan. 2003. Effects of final implant type and supplementation of melengestrol acetate on finishing heifer performance, carcass characteristics, and feeding economics. Prof. Anim. Sci. 19:159.

Mader, T. L., and K. F. Lechtenberg. 2000. Growth-promoting systems for heifer calves and yearlings finished in the feedlot. J. Anim. Sci. 78:2485

McKenna, D. R., D. L. Roeber, P. K. Bates, T. B. Schmidt, D. S. Hale, D. B. Griffin, J. W. Savell, J. C. Brooks, J. B. Morgan, T. H. Montgomery, K. E. Belk, and G. C. Smith. 2002. National Beef Quality Audit-2000: Survey of targeted cattle and carcass characteristics related to quality, quantity, and value of fed steers and heifers. J. Anim. Sci. $80: 1212$

Moseley, W. M., D. M. Meeuwse, J. F. Boucher, K. J. Dame, and J. W. Lauderdale. 2003. A dose-response study of melengestrol acetate on feedlot performance and carcass characteristics of beef steers. J. Anim. Sci. 81:2699

NRC. 1996. Nutrient Requirements of Beef Cattle. 7th rev. ed. Natl. Acad. Press, Washington, DC.

O'Brien, C. A., R. E. Bloss, and E. F. Nicks. 1968. Effect of melengestrol acetate on the growth and reproductive physiology of fattening heifers. J. Anim. Sci. 27:664.

Purchas, R. W., K. L. Macmillan, and H. D. Hafs. 1970. Pituitary and plasma growth hormone levels in bulls from birth to one year of age. J. Anim. Sci. 31:358.

Purchas, R. W., A. M. Pearson, H. D. Hafs, and H. A. Tucker. 1971. Some endocrine in- fluences on the growth and carcass quality of Holstein heifers. J. Anim. Sci. 33:836.

Romans, J. R., J. E. McClendon, S. L. Moore, and A. L. Neumann. 1988. Characterization of heifer beef color related to natural onset of estrus and estrus onset caused by withdrawal of melengestrol acetate. p. 231 in Proc 34th Int. Congr. Meat Sci. and Technol. CSIRO Meat Research Laboratory, Brisbane, Australia.

Roussel, J. D., and J. F. Beatty. 1969. Effect of melengestrol acetate on synchronization of estrus, subsequent fertility and milk constituents of lactation dairy cows. J. Dairy Sci. 52:2020.

Scanga, J. A., K. E. Belk, J. D. Tatum, T. Grandin, and G. C. Smith. 1998. Factors contributing to the incidence of dark cutting beef. J. Anim. Sci. 76:2040.

USDA. 2008. National Weekly Direct Slaughter Cattle-Premiums and Discounts for the Week of 4/7/2008. http://www.ams.usda. gov/mnreports/lm_ct155.txt Accessed April 11, 2008.

US Food and Drug Administration. 1968. Melengestrol acetate. p. 419 in The Code of Federal Regulations, Section 558.342. Food and Drug Admin., Washington, DC.

Voisinet, B. D., T. Grandin, J. D. Tatum, S. F. O'Connor, and J. J. Struthers. 1997. Feedlot cattle with calm temperaments have higher average daily gains that cattle with excitable temperaments. J. Anim. Sci. 75:982.

Wettemann, R. P., H. D. Hafs, and D. A. Marrow. 1973. Luteinizing hormone, prolactin, and interval to ovulation after melengestrol acetate in cattle. J. Dairy Sci. 56:261.

Young, A. W., L. V. Cundiff, and N. W. Bradley. 1969. Effects of an oral progestogen on feedlot heifers. J. Anim. Sci. 28:224

Zimbelman, R. G., and L. W. Smith. 1966. Control of ovulation in cattle with melengestrol acetate. II. Effects of follicular size and activity. J. Reprod. Fertil. 11:193. 